\title{
Fenugreek Seed Extract Alleviates Hippocampal Dendritic Atrophy in Streptozotocin Induced Diabetic Rats
}

\author{
El Extracto de Semillas Fenugreek Alivia la Atrofía Dendrítica del \\ Hipocampo en Ratas Diabéticas Inducidas por Estreptozotocina
}

\author{
Praveen Kumar Kodumuri'; Anil Kumar Pandey² \& Christofer Thomas ${ }^{3}$
}

KODUMURI, P. K.; PANDEY, A. K. \& THOMAS, C. Fenugreek seed extract alleviates hippocampal dendritic atrophy in streptozotocin induced diabetic rats. Int. J. Morphol., 38(6):1693-1699, 2020.

SUMMARY: Herbal extracts used for treatment of diabetes has focused mostly on the hypoglycaemic and anti-oxidant property.There are no studies which focused on its effect on dendritic architecture of pyramidal neurons of hippocampus caused by diabetes. This study was taken up to explore the effect of administration of Trigonella foenum-graecum (fenugreek) seed extract on diabetes induced dendritic atrophy in hippocampus. Experimental diabetes was induced in rats by administering single dose of Streptozotocin $(60 \mathrm{mg} / \mathrm{kg})$ intraperitoneally.Treatment groups of rats were orally administeredfenugreek seed extract of $1 \mathrm{~g} / \mathrm{kg}$ body weight for 6 weeks. Followingly they were sacrificed and the brains were removed, processed for the Golgi-Cox stain method.The number of dendritic branching points and intersections were counted in successive radial segments of $20 \mu \mathrm{m}$ up to a radial distance of 100 micron from soma and analysed by the Sholl's method. The rats with diabetes showed a significant decrease in the dendritic length and branching points in most of the apical and basal dendrites of CA1 and CA3 pyramidal neurons.Treatment with fenugreek seed extract were able to significantly alleviate the dendritic atrophy in most of the segments except in the apical branching points of the CA1 neuron. The present study demonstrates that fenugreek seed extract having a proven hypoglycaemic and anti-diabetic property also possess protection to the hippocampal pyramidal neurons form diabetes associated neuronal atrophy.

KEY WORDS: Diabetes; Dendritic atrophy; Fenugreek; Hippocampus.

\section{INTRODUCTION}

It is a well-established fact in both humans and in animal models that one of the complications of diabetes mellitus is neuropathy which involves both peripheral and central nerve tissues. Central nervous tissue involvement in diabetic complications may manifest as impairment of learning, cognition and memory (Parihar et al., 2004).This phenomenon is due to the diabetes induced pathological changes in the central nervous system which is recently termed as diabetes associated cognitive decline (DACD) (Biessels \& Gispen, 2005). The reasons for DACD is due to impaired neuronal plasticity, altered neurotransmission, dendritic atrophy, altered neurotrophic factors and reduced neurogenesis which has been shown using experimental diabetic animal models (Magariños \& McEwen, 2000). Whereas in the case of human subjects, it has been shown that changes include smaller volume of grey matter (Jongen et al., 2007), lower brain-to-intracranial volume ratios
(Christman et al., 2010) and grey matter atrophy. And hence this metabolic disorder is considered as a potential risk factor for dementia (Nitta et al., 2002) depression, and Alzheimer's disease (Anderson et al., 2001; Gasparini et al., 2002).

In particular, using animal models for diabetes, there have been reports that there is impairment in learning and in particular, hippocampal dependent learning memory tasks (Biessels \& Gispen). Dendritic atrophy was shown in terms of reduction in total dendritic lengths, total branching points and reduction in spine densities. These changes at the cellular levels and along with alterations in neurotransmitter levels in the hippocampal regions could be one of the reasons of diabetes induced cognitive impairment (Kamal et al., 2000). Apart from dendritic atrophy in the hippocampus, decreased neurogenesis is also shown to be decreased in animal models

\footnotetext{
${ }^{1}$ Department of Physiology, TomoRiba Institute of Health \& Medical Sciences, Naharlagun, Arunachal Pradesh, India.

${ }^{2}$ Department of Physiology, ESIC Medical College \& Hospital, Faridabad, Haryana, India.

${ }^{3}$ Department of Physiology, All India Institute of Medical Sciences, Kalyani, West Bengal, India.
} 
of diabetes (Zhang et al., 2008). It is an established fact that decreased neurogenesis is associated with impaired hippocampal dependent learning and memory(Eriksson \& Wallin, 2004).

Most of the routine anti-diabetic drugs is shown to exhibit adverse side effects on cardiovascular system and has minimal effect on addressing the cognitive decline associate with diabetes. Considering this, there is a necessity to look for alternative therapeutic strategies to combat the cognitive complications associated with diabetes with minimal or no side effects. Among alternative strategies, is the use of medicinal plants which have a therapeutic potential. Among the 21,000 medicinal plans listed by World Health Organization, 800 plants are reported to have antidiabetic properties (Patil et al., 2011). Most of the studies which explored the antidiabetic properties of these medicinal plants have not explored the cognitive aspect and there are few reports suggesting the effect of herbal medicine treatment on the dendritic morphology in diabetic animal models.

Based on the review of herbal medicinal plant have antidiabetic properties, we selected Trigonella foenumgraecum (Fenugreek) for the present study (Medagama et al., 2014). Fenugreek is a plant belonging to the family leguminosae and it is often used as a spice as well as a medicine around the world. Seeds and leaves are the most frequently used parts of the plant and have shown to have many pharmacological properties such as antidiabetic, antinociceptive, anti-carcinogenic, antioxidant, anti-inflammatory, and hypo-cholesterolemic effect (Goyal et al., 2016).

Blood glucose lowering property of fenugreek is well established, but whether it has a role in ameliorating dendritic atrophy associated with diabetes remains elusive. Hence this study was undertaken to explore the effect of fenugreek seed extract on the dendritic architecture in the hippocampal pyramidal neurons in streptozotocin induced diabetic rats.

\section{MATERIAL AND METHOD}

Adult male Wistar rats (200-220 g) were procured from National Centre for Laboratory Animal Sciences (NCLAS), National Institute of Nutrition (ICMR), Hyderabad. All experiments were conducted as per the National Institute of Health Guidelines for the Care and Use of Mammals in Neuroscience and Behavioral Research (The National Academics Press, Washington USA, 2003) after obtaining the institutional animal ethics committee (IAEC) approval (10/IAEC/MMC/Ph.D./2013-14) from Mamata medical collge, Khammam(Telangana state, India).
Animals were randomly assigned to three groups( $\mathrm{n}=6$ in each group), namely, Normal control group (NC), Diabetic control group(DC) which received a single dose of Streptozotocin 60 mg/kg (Sisco Research Laboratories Pvt. Ltd., Mumbai) intraperitoneally (Bhatnagar et al., 2005) and Diabetic rats which received fenugreek seed extract $1 \mathrm{~g} / \mathrm{Kg}$ body weight for 6 weeks orally (DC+Tfg). Fenugreek seed extract was prepared using standardized protocol described earlier (Basch et al., 2003; Vijayakumar et al., 2005). Blood glucose levels and body weight were measured before commencement of study and at the end of study using a glucometer (Ascensia,USA) and animal weighing scale.

Golgi Cox staining procedure. Quantification of dendritic branching points and intersections of CA3 and CA1 pyramidal neurons of the hippocampus was done by GolgiCox staining procedure. After 6 weeks of experiment, all rats were deeply anesthetized using pentobarbital sodium, and were decapitated quickly. Subsequently, brains were quickly removed and staining done using Golgi-cox solution. After staining, coronal sections were taken at a thickness of 120 microns' using a base sledge microtome and sections were collected serially, dehydrated in absolute alcohol, cleared in xylene and cover-slipped. Slides were coded prior to quantitative analysis and the code was broken only after the analysis was completed. The Golgi-impregnated neurons chosen for analysis had to satisfy the following criteria: (a) presence of untruncated dendrites; (b) consistent and dark impregnation along the entire extent of all dendrites and (c) relative isolation from neighboring impregnated neurons to avoid interference with analysis. Representative image of CA3 neurons after Golgi staining is shown in Figure 1.Ten CA1 and CA 3 pyramidal neurons of dorsal hippocampus were considered for morphological quantification and their camera lucida tracings (625X) were obtained. The number of dendritic branching points and intersections was counted in successive radial segments of $20 \mu \mathrm{m}$ by Sholl's method using center of

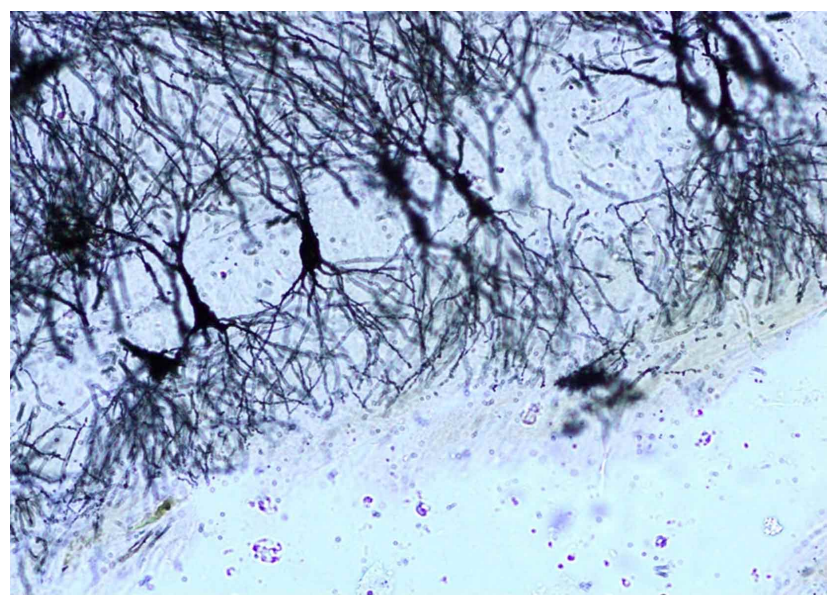

Fig. 1. Representative image of CA3 neurons after Golgi staining. 
the soma as reference points shown in Figure 2. Both branching points and intersections were counted up to a radial distance of 100micron from the center of the soma.

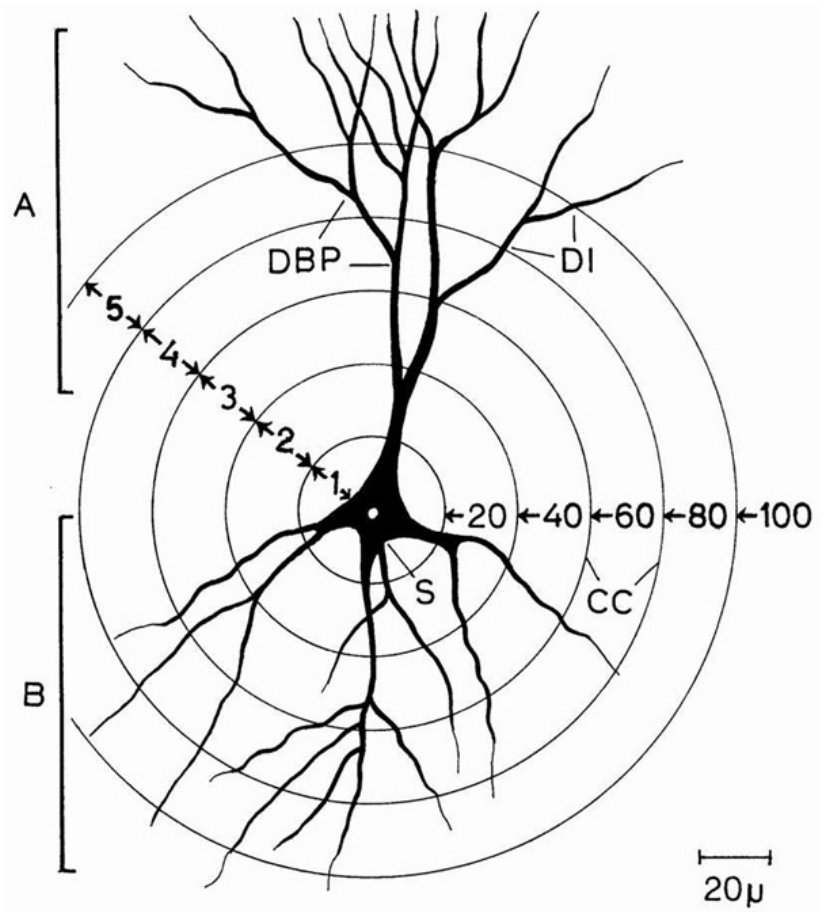

Fig. 2. Quantification of intersections and branching points using Sholl's method. A- Apical dendrites, B- Basal dendrites, DBPdendritic branching points, DI- Dendritic intersections, S- soma, $\mathrm{CC}$ - concentric circles

Statistical analysis. Results were expressed as mean \pm S.E.M. The data were analysed by one-way analysis of variance (ANOVA) followed by Tukey's comparison tests. Statistical significance was considered at $\mathrm{P}<0.05$ in all cases.

\section{RESULTS}

Conformation of induction of Diabetes using body weight and blood glucose. Body weight and blood glucose parameters were checked for the conformation of induction of diabetes. Both these parameters were measured both at two intervals; one at the beginning of the study and second was after 15 days. Induction of diabetes was confirmed by the increased blood glucose levels in the STZ group compared to the normal control group whose blood glucose levels did not alter significantly between two time points (Fig. 3).

\section{Effect of fenugreek treatment on the structural changes of Hippocampal CA1 pyramidal neurons}

Basal Dendrites: Data on dendritic intersections and branching points in basal dendrites when subjected to ANOVA revealed a significant effect between groups and segments $(\mathrm{P}<0.0001)$ and were decreased in all the segments of DC group compared to the controls (Table I). Treatment of fenugreekwas prevented the reductions of intersections in the segments except 0-20 and 80-100 $(p<0.001)$ and for the branching points except the last segment as seen in Table I.

Apical Dendrites. Statistical analysis of the number of intersections and branching points in apical dendrites showed a significant difference between groups and segments $(\mathrm{p}<0.0001, \mathrm{p}<0.001)$. There was a decrease in the number of intersections in all segments $(\mathrm{p}<0.001$, Table II) with the exception of 0-20 segment, and decrease in the number of dendritic branching points in the segments except
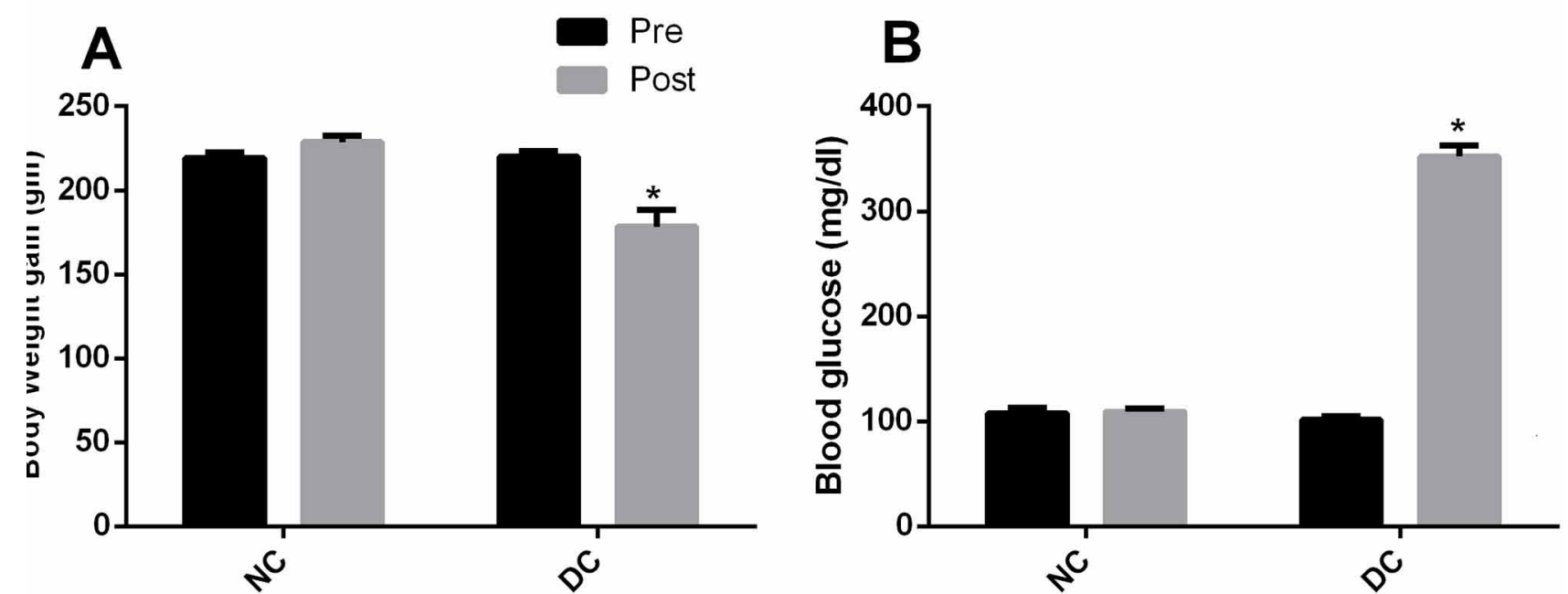

Fig. 3. Induction of diabetes was conformed by decreased body weight gain (A) and increased blood glucose level (B). *p<0.05, student's ttest. 
0-20 and 20-40 ( $\mathrm{p}<0.05)$ of the DC group of animals compared to control groups. Treatment with fenugreek significantly prevented this reduction on intersections in $40-60$ and $60-80$ segments $(\mathrm{p}<0.01, \mathrm{p}<0.05)$ compared to DC group of animals wheras fenugreek did not have a significant effect on branching points in Diabetic control group of rats (Table II).

\section{Effect of Tfg treatment on the structural changes of Hippocampal CA3 pyramidal neurons}

Basal Dendrites. Data on dendritic intersections and branching points in basal dendrites when subjected to ANOVA also revealed a significant difference between groups and segments $(\mathrm{P}<0.0001)$. The dendritic intersections were decreased in all the segments of the DC group compared to the controls ( $\mathrm{p}<0.001)$ and interestingly, treatment with fenugreek prevented this effect in all the segments compared to DC group ( $\mathrm{p}<0.001$, Table III). Wheras segments 20-40 and 40-60 showed ameliorative effect with fenugreek treatment on branching points in the DC group of animals ( $<<0.05$, Table III).

Apical Dendrites. Analysis of the number of intersections and branching points in apical dendrites showed a significant difference between groups and segments $(\mathrm{P}<0.0001)$. There was a significant decrease in the number of intersections in all the segments except 0-20 of the DC group of animals compared to the control groups ( $p<0.05$, $\mathrm{p}<0.001$, Table IV). Diabetic control group of animals received fenugreek treatment showed restorative effect in segments except 0-20 and 20-40 compared to DC rats. $(\mathrm{p}<0.01, \mathrm{P}<0.001)$. wheras treatment with fenugreek showed the reversal of branching points only in the last three segments $(\mathrm{p}<0.01, \mathrm{p}<0.001)$ compared to the DC group.

Table I. Number of dendritic intersections and branching points in basal dendrites of CA1 pyramidal neurons.

\begin{tabular}{|c|c|c|c|c|c|}
\hline \multicolumn{6}{|c|}{ Segments $(20 \mu \mathrm{m})$} \\
\hline & $0-20$ & $20-40$ & $40-60$ & $60-80$ & $80-100$ \\
\hline \multicolumn{6}{|c|}{ I. CA1 Basal Dendritic Intersections } \\
\hline $\mathrm{NC}$ & $3.72 \pm 0.27$ & $8.12 \pm 0.21$ & $13.86 \pm 0.38$ & $8.12 \pm 0.21$ & $3.24 \pm 0.32$ \\
\hline $\mathrm{DC}$ & $1.87 \pm 0.24^{* * *}$ & $3.12 \pm 0.25^{* * *}$ & $5.55 \pm 0.34^{* * *}$ & $3.59 \pm 0.25^{* * *}$ & $1.31 \pm 0.35^{* * *}$ \\
\hline $\mathrm{DC}+\mathrm{TfG}$ & $2.26 \pm 0.19$ & $5.09 \pm 0.28 \# \#$ & $8.49 \pm 0.31 \ldots \#$ & $6.11 \pm 0.26$ & $2.26 \pm 0.34$ \\
\hline \multicolumn{6}{|c|}{$\mathrm{F}(4,100)=467.9, \mathrm{P}<0.0001$} \\
\hline$* * * \mathrm{p}<0$. & $\mathrm{p}<0.01$ vs $\mathrm{NC}$, & 01 vs DC, Two & JOVA with Tuk & le comprico & \\
\hline \multicolumn{6}{|c|}{ II. CA1 Basal Branching Points } \\
\hline $\mathrm{NC}$ & $1.56 \pm 0.13$ & $2.85 \pm 0.04$ & $4.23 \pm 0.08$ & $2.93 \pm 0.15$ & $0.98 \pm 0.11$ \\
\hline $\mathrm{DC}$ & $0.52 \pm 0.11^{\text {*** }}$ & $1.13 \pm 0.05^{* * *}$ & $1.53 \pm 0.07^{* * *}$ & $0.97 \pm 0.12^{* * *}$ & $0.41 \pm 0.09^{* *}$ \\
\hline $\mathrm{DC}+\mathrm{TfG}$ & $0.98 \pm 0.12 \#$ & $1.78 \pm 0.05 \# \#$ & $2.64 \pm 0.06 \# \#$ & $1.83 \pm 0.12$ & $0.61 \pm 0.09$ \\
\hline \multicolumn{6}{|c|}{$F(4,100)=346.6, P<0.0001$} \\
\hline Table I: $* *$ & $0.001, * * \mathrm{p}<0.0$ & \#\#\# p<0.001, \#\# & $\# p<0.05$ Vs DC & ANUVA With & s multiple \\
\hline
\end{tabular}

Table II. Number of dendritic intersections and branching points in Apical dendrites of CA1 pyramidal neurons.

\begin{tabular}{|c|c|c|c|c|c|}
\hline \multicolumn{6}{|c|}{ Segments $(20 \mu \mathrm{m})$} \\
\hline & $0-20$ & $20-40$ & $40-60$ & $60-80$ & $80-100$ \\
\hline \multicolumn{6}{|c|}{ I. CA1 Apical Dendritic Intersections } \\
\hline $\mathrm{NC}$ & $0.94 \pm 0.14$ & $2.36 \pm 0.19$ & $3.29 \pm 0.11$ & $5.21 \pm 0.31$ & $5.28 \pm 0.38$ \\
\hline $\mathrm{DC}$ & $0.31 \pm 0.15$ & $0.87 \pm 0.19^{* * *}$ & $1.14 \pm 0.24^{* * *}$ & $2.73 \pm 0.31^{* * *}$ & $2.68 \pm 0.36^{* * * *}$ \\
\hline $\mathrm{DC}+\mathrm{TfG}$ & $0.54 \pm 0.25$ & $1.12 \pm 0.21$ & $2.16 \pm 0.27^{\#}$ & $3.68 \pm 0.32 \#$ & $3.48 \pm 0.31$ \\
\hline \multicolumn{6}{|c|}{$\mathrm{F}(4,100)=144.2, \mathrm{P}<0.0001$} \\
\hline \multicolumn{6}{|c|}{$* * * \mathrm{p}<0.001, * * \mathrm{p}<0.01 \mathrm{vs} \mathrm{NC}, \# \# \# \mathrm{p}<0.001, \# \mathrm{p}<0.05$ vs DC, Two way ANOVA with Tukey's multiple comparison test } \\
\hline \multicolumn{6}{|c|}{ II. CA1 Apical Branching Points } \\
\hline $\mathrm{NC}$ & $0.34 \pm 0.11$ & $0.71 \pm 0.09$ & $0.97 \pm 0.05$ & $1.24 \pm 0.19$ & $1.15 \pm 0.22$ \\
\hline $\mathrm{DC}$ & $0.12 \pm 0.13$ & $0.14 \pm 0.1$ & $0.28 \pm 0.09^{*}$ & $0.52 \pm 0.21^{*}$ & $0.48 \pm 0.18^{*}$ \\
\hline $\mathrm{DC}+\mathrm{TfG}$ & $0.24 \pm 0.18$ & $0.59 \pm 0.15$ & $0.69 \pm 0.14$ & $0.84 \pm 0.27$ & $0.89 \pm 0.19$ \\
\hline \multicolumn{6}{|c|}{$\mathrm{F}(4,100)=12.51, \mathrm{P}<0.0001$} \\
\hline Table II: * & 05 vs NC, \# p & Two way AN & thes de & & \\
\hline
\end{tabular}


Table III. Number of dendritic intersections and branching points in Basal dendrites of CA3 pyramidal neurons.

\begin{tabular}{|c|c|c|c|c|c|}
\hline \multicolumn{6}{|c|}{ Segments $(20 \mu \mathrm{m})$} \\
\hline & $0-20$ & $20-40$ & $40-60$ & $60-80$ & $80-100$ \\
\hline \multicolumn{6}{|c|}{ I. CA3 Basal Dendritic Intersections } \\
\hline $\mathrm{NC}$ & $6.18 \pm 0.17$ & $12.42 \pm 0.28$ & $16.29 \pm 0.26$ & $17.34 \pm 0.21$ & $13.14 \pm 0.22$ \\
\hline DC & $3.15 \pm 0.28^{* * *}$ & $7.13 \pm 0.31^{\text {*** }}$ & $8.23 \pm 0.42^{* * *}$ & $9.14 \pm 0.25^{* * *}$ & $7.82 \pm 0.22^{* * *}$ \\
\hline $\mathrm{DC}+\mathrm{TfG}$ & $4.86 \pm 0.16$ & $10.23 \pm 0.31^{\# \# \#}$ & $12.07 \pm 0.28^{\# \# \#}$ & $13.67 \pm 0.22^{\# \# \#}$ & $10.98 \pm 0.18 \# \#$ \\
\hline \multicolumn{6}{|c|}{$\mathrm{F}(4,100)=777.0, \mathrm{P}<0.0001$} \\
\hline \multicolumn{6}{|c|}{ *** $\mathrm{p}<0.001$ vs NC, \#\#\# $\mathrm{p}<0.001$ vs DC, Two way ANOVA with Tukey's multiple comparison test } \\
\hline \multicolumn{6}{|c|}{ II. CA3 Basal Branching Points } \\
\hline $\mathrm{NC}$ & $1.59 \pm 0.23$ & $6.34 \pm 0.21$ & $5.68 \pm 0.25$ & $4.22 \pm 0.16$ & $1.52 \pm 0.15$ \\
\hline $\mathrm{DC}$ & $0.48 \pm 0.22 *$ & $2.07 \pm 0.31^{* * *}$ & $2.14 \pm 0.29^{* * * *}$ & $1.37 \pm 0.26^{* * *}$ & $0.42 \pm 0.28^{*}$ \\
\hline $\mathrm{DC}+\mathrm{TfG}$ & $0.79 \pm 0.18$ & $3.15 \pm 0.26 \#$ & $3.21 \pm 0.14 \#$ & $2.16 \pm 0.22$ & $0.72 \pm 0.72$ \\
\hline \multicolumn{6}{|c|}{$\mathrm{F}(4,100)=146.7, \mathrm{P}<0.0001$} \\
\hline Table III: & $<0.001, * \mathrm{p}<0.0$ & $\# \# \# \mathrm{p}<0.001$ & $\mathrm{DG}$ & & \\
\hline
\end{tabular}

Table IV. Number of dendritic intersections and branching points in Apical dendrites of CA3 pyramidal neurons.

\begin{tabular}{|c|c|c|c|c|c|}
\hline \multicolumn{6}{|c|}{ Segments $(20 \mu \mathrm{m})$} \\
\hline & $0-20$ & $20-40$ & $40-60$ & $60-80$ & $80-100$ \\
\hline \multicolumn{6}{|c|}{ I. CA3 Apical Dendritic Intersections } \\
\hline $\mathrm{NC}$ & $0.38 \pm 0.07$ & $1.23 \pm 0.04$ & $1.82 \pm 0.16$ & $2.56 \pm 0.32$ & $3.68 \pm 0.19$ \\
\hline $\mathrm{DC}$ & $0.24 \pm 0.12$ & $0.39 \pm 0.17 *$ & $0.42 \pm 0.19^{* * *}$ & $0.82 \pm 0.38^{* * *}$ & $1.24 \pm 0.26^{* * *}$ \\
\hline $\mathrm{DC}+\mathrm{TfG}$ & $0.32 \pm 0.11$ & $0.92 \pm 0.13$ & $1.25 \pm 0.12^{\#}$ & $1.76 \pm 0.28 \#$ & $2.83 \pm 0.21 \ldots \#$ \\
\hline \multicolumn{6}{|c|}{$\begin{array}{l}\mathrm{F}(4,100)=97.74, \mathrm{P}<0.0001 \\
* * * \mathrm{p}<0.001, * \mathrm{p}<0.05 \text { vs NC, \#\#\# } \mathrm{p}<0.001, \# \# \mathrm{p}<0.01 \text { vs DC, Two way ANOVA with Tukey's multiple comparison test }\end{array}$} \\
\hline \multicolumn{6}{|c|}{ II. CA3 Apical Branching Points } \\
\hline NC & $1.32 \pm 0.14$ & $2.27 \pm 0.11$ & $3.56 \pm 0.28$ & $6.34 \pm 0.19$ & $8.18 \pm 0.12$ \\
\hline DC & $0.47 \pm 0.25^{*}$ & $0.68 \pm 0.19^{* * *}$ & $1.14 \pm 0.35^{* * *}$ & $1.48 \pm 0.23^{* * *}$ & $2.14 \pm 0.26^{* * *}$ \\
\hline $\mathrm{DC}+\mathrm{TfG}$ & $0.68 \pm 0.25$ & $1.28 \pm 0.19$ & $2.31 \pm 0.26^{\# \#}$ & $3.82 \pm 0.25 \# \#$ & $5.12 \pm 0.22$ \\
\hline
\end{tabular}

$\mathrm{F}(4,100)=342.8, \mathrm{P}<0.0001$

Table IV. $* * * \mathrm{p}<0.001,{ }^{*} \mathrm{p}<0.05$ vs NC, \#\#\# p<0.001, \#\# p<0.01 vs DC, Two way ANOVA with Tukey's multiple comparison test

\section{DISCUSSION}

The current study was undertaken to investigate the role of Fenugreek seed extracton diabetes-induced hippocampal dendritic atrophy. The results from this study have shown that Streptozotocin induced diabetes in rats showed decreased neuronal arborization in both CA1 and CA3 neurons in the hippocampus. Treatment with fenugreek extract significantly prevented the hippocampal dendritic atrophy. In the present study, rats were injected with a single dose of STZ (60 mg/kgbwt) intraperitoneal which is a validated the model for diabetic features which included hyperglycaemia and weight loss which were consistent with other studies (Radenkovic et al., 2016). Our results also showed that diabetic animals treated with Tfg showed significant reduction in blood glucose levels and maintained body weight compared to the diabetic rats.

Diabetes has been reported to cause neurodegenerative changes in the hippocampus which is linked to memory loss. Experimental studies on Streptozotocin -induced diabetic rats showed neuropathological changes such as dark neurons and neuronal loss with reduced length, arborization and decreased density of the dendritic spines in the hippocampus (Sanchez-Vega et al., 2015). In current study, decrease in the dendritic arbors in diabetic rat hippocampus were consistent with the previous reports which indicate similar changes in the hippocampus (Zhang et al., 2015). The reasons for diabetes-inducted degeneration of neurons could be multifactorial like oxidative stress, apoptosis, glutamate toxicity, decrease in anti-oxidant enzymes and reduction in the neurotrophic factors.

It was reported that, persistent hyperglycemia in diabetes leads to activation of polyol-sorbitol pathways which leads to the accumulation of reactive oxygen species in the hippocampus region resulting in neuronal apoptosis 
(Pugazhenthi et al., 2003). It is also reported that proteins facilitating apoptotic cell death like Bax and caspase-3 were elevated in hippocampus of diabetic rats (Piotrowski et al., 2001). In addition, in the hippocampus of the diabetic rats, the activity of superoxide dismutase, glutathione peroxidase and catalase, anti-oxidant enzymes, are reduced (Mao et al., 2014; Kodumuri et al., 2019) and elevated levels of glutamate (Stem \& Gardner, 2013). Therefore, it can be hypothesized that hippocampal neurons of STZ-treated rats showed regressive plasticity due to the glutamate induced excitotoxicity and reduced anti-oxidants levels. This increase in glutamate levels is substantiated by an altered level of glutamate receptor like AMPA, NMDA and mGlu5 receptors in diabetic rats (Jayanarayanan et al., 2013). Neurotropic factors like brain derived neurotropic factor (BDNF) is considered as a crucial molecule in the regulation of dendritic arbors and number of spines (Bennettet \& Lagopoulos, 2014). It has been reported that in the hippocampus of STZinduced diabetes in rats, BDNF content and expression has been reduced (Agrawal et al., 2014).

The components responsible and the mechanism by which fenugreek seed extract exerts their effects are not clearly understood. Literature has already established the antihyperglycemic and anti-oxidant properties of the fenugreek and hence it can be postulated that these two properties could be the reason for the prevention of dendritic atrophy associated with diabetes.It has been shown that the administration of fenugreek seed powder to diabetic rats was able to decrease the blood glucose (Vats et al., 2003; Yadav et al., 2004). The mechanism by which fenugreek extract decreases blood glucose is by inhibiting intestinal glucose uptake (Al-Habori et al., 2001). The active components of fenugreek seed extract for this anti-hyperglycemic property is saponin compounds (Goyal et al.). It has been showed that peripheral hyperglycemia caused significant increases in brain sorbitol and inositol and reduced taurine which was associated with reduced dendritic branching and spine density in hyperglycemic rats but not in hypoglycemic animals. In addition, these hyperglycemic animals showed impaired spatial memory in water maze task (Malone et al., 2008). A recent study by Kodumuri et al. has shown that diabetic rats administered with fenugreek seed extract showed improved spatial learning and memory. These animals also showed decreased blood glucose levels, decreased oxidative stressmarkers in hippocampus, decreased neuronal loss from CA1 and CA3 regions of hippocampus. Acetyl choline esterase inhibitory activity of fenugreek seed is well established (Satheeshkumar et al., 2010) and this also could be one possible reason for the improvement of memory and prevention of dendritic atrophy in diabetic rats. Another recent study by Bafadam et al. (2019) has also shown promising results in ameliorating cognitive deficits associated with diabetes with the administration of fenugreek seed extract. In the background of these promising results, we hypothesize that the antihyperglycemic, antioxidant and acetyl choline esterase property of the fenugreek seeds could be the reason for the prevention of dendritic atrophy seen in diabetic animals treated with fenugreek seed extract. But to elucidate the exact mechanism of this ameliorative effect, and to examine its potential clinical use further studies are necessary. These extracts need to be adequately and carefully examined further using electrophysiological and molecular markers which might enhance the scope of study on the effects of fenugreek seed extract on diabetes-induced learning and memory impairment.

In summary, our results showed that there was dendritic atrophy in the pyramidal neurons of the hippocampus in both CA1 and CA3 regions in the diabetic control rats. Dendritic atrophy was evident in both the apical and basal regions of these pyramidal cells in the regions evaluated. Treatment with fenugreek seed extract significantly prevented this regressive plasticity observed in the diabetic control group of rats. We propose that antihyperglycemic and antioxidant property of the fenugreek seed could be a potential reason for this effect.

KODUMURI, P. K.; PANDEY, A. K. \& THOMAS, C. El extracto de semillas fenugreek alivia la atrofía dendrítica del hipocampo en ratas diabéticas inducidas por estreptozotocina. Int. J. Morphol. 38(6):1693-1699, 2020.

RESUMEN: Los extractos de hierbas para el tratamiento de la diabetes se han basado principalmente en las propiedades hipoglucémicas y antioxidantes. En la literatura no hay estudios basados en su efecto sobre la arquitectura dendrítica de las neuronas piramidales del hipocampo, causadas por la diabetes. El objetivo de este estudio fue investigar el efecto de la administración de extracto de semilla de Trigonella foenum graecum (fenogreco) sobre la atrofia dendrítica inducida por la diabetes en el hipocampo. Se indujo diabetes experimental en ratas mediante la administración de una dosis única de estreptozotocina $(60 \mathrm{mg} / \mathrm{kg}$ ) por vía intraperitoneal. Se administró a grupos de ratas extracto de semilla de fenogreco a razón de $1 \mathrm{~g} / \mathrm{kg}$ de peso corporal durante 6 semanas. Las ratas fueron sacrificadas posteriormente y se procesaron los cerebros mediante método de tinción de Golgi-Cox. El número de puntos de ramificación dendrítica e intersecciones se contaron en segmentos radiales sucesivos de $20 \mu \mathrm{m}$ hasta una distancia radial de 100 micras del soma y se analizaron mediante el método de Sholl. Las ratas con diabetes mostraron una disminución significativa en la longitud dendrítica y los puntos de ramificación en la mayoría de las dendritas apicales y basales de las neuronas piramidales CA1 y CA3. El tratamiento con extracto de semilla de fenogreco alivió significativamente la atrofia dendrítica en la mayoría de los casos, excepto en los puntos de ramificación apical de la neurona CA1. El estudio demuestra que el extracto de semilla de fenogreco además de tener propiedades hipoglucémicas y antidiabéticas, también protege las neuronas 
piramidales del hipocampo contra la atrofia neuronal asociada a la diabetes.

PALABRAS CLAVE: Diabetes; Atrofia dendrítica; Fenogreco; Hipocampo.

\section{REFERENCES}

Agrawal, R.; Zhuang, Y.; Cummings, B. P.; Stanhope, K. L.; Graham, J. L.; Havel, P. J. \& Gomez-Pinilla, F. Deterioration of plasticity and metabolic homeostasis in the brain of the UCD-T2DM rat model of naturally occurring type-2 diabetes. Biochim. Biophys. Acta, 1842(9):1313-23, 2014.

Al-Habori, M.; Raman, A.; Lawrence, M. J. \& Skett, P. In vitro effect of fenugreek extracts on intestinal sodium-dependent glucose uptake and hepatic glycogen phosphorylase A. Int. J. Exp. Diabetes Res., 2(2):91-9, 2001.

Anderson, R. J.; Freedland, K. E.; Clouse, R. E. \& Lustman, P. J. The prevalence of comorbid depression in adults with diabetes: a meta-analysis. Diabetes Care, 24(6):1069-78, 2001.

Bafadam, S.; Beheshti, F.; Khodabakhshi, T.; Asghari, A.; Ebrahimi, B.; Sadeghnia, H. R.; Mahmoudabady, M.; Niazmand, S. \& Hosseini, M. Trigonella foenumgraceum seed (Fenugreek) hydroalcoholic extract improved the oxidative stress status in a rat model of diabetes-induced memory impairment. Horm. Mol. Biol. Clin. Investig., 39(2):2019. DOI: https://www.doi.org/10.1515/ hmbci-2018-0074

Basch, E.; Ulbricht, C.; Kuo, G.; Szapary, P. \& Smith, M. Therapeutic applications of fenugreek. Altern. Med. Rev., 8(1):20-7, 2003.

Bennett, M. R. \& Lagopoulos, J. Stress and trauma: BDNF control of dendriticspine formation and regression. Prog. Neurobiol., 112:80-99, 2014.

Bhatnagar, M.; Shukla, S. D. \& Bhatnagar, R. Experimental neurodegeneration in hippocampus and its phytoremidation. J. Herb. Pharmacother., 5(2):21$30,2005$.

Biessels, G. J. \& Gispen, W. H. The impact of diabetes on cognition: what can be learned from rodent models? Neurobiol. Aging, 26 Suppl. 1:36-41, 2005.

Christman, A. L.; Vannorsdall, T. D.; Pearlson, G. D.; Hill-Briggs, F. \& Schretlen, D. J. Cranial volume, mild cognitive deficits, and functional limitations associated with diabetes in a community sample. Arch. Clin. Neuropsychol., 25(1):49-59, 2010.

Eriksson, P. S. \& Wallin, L. Functional consequences of stress-related suppression of adult hippocampal neurogenesis - a novel hypothesis on the neurobiology of burnout. Acta Neurol. Scand., 110(5):275-80, 2004.

Gasparini, L.; Netzer, W. J.; Greengard, P. \& Xu, H. Does insulin dysfunction play a role in Alzheimer's disease? Trends Pharmacol. Sci., 23(6):288-93, 2002.

Goyal, S.; Gupta, N. \& Chatterjee, S. Investigating therapeutic potential of Trigonella foenum-graecum L. as our defense mechanism against several human diseases. J. Toxicol., 2016:1250387, 2016.

Jayanarayanan, S.; Smijin, S.; Peeyush, K. T.; Anju, T. R. \& Paulose, C. S. NMDA and AMPA receptor mediated excitotoxicity in cerebral cortex of streptozotocin induced diabetic rat: ameliorating effects of curcumin. Chem. Biol. Interact., 201(1-3):39-48, 2013.

Jongen, C.; van der Grond, J.; Kappelle, L. J.; Biessels, G. J.; Viergever, M. A.; Pluim, J. P. \& Utrecht Diabetic Encephalopathy Study Group. Automated measurement of brain and white matter lesion volume in type 2 diabetes mellitus. Diabetologia, 50(7):1509-16, 2007.

Kamal, A.; Biessels, G. J.; Duis, S. E. \& Gispen, W. H. Learning and hippocampal synaptic plasticity in streptozotocin-diabetic rats: interaction of diabetes and ageing. Diabetologia, 43(4):500-6, 2000.

Kodumuri, P. K.; Thomas, C.; Jetti, R. \& Pandey, A. xsK. Fenugreek seed extract ameliorates cognitive deficits in streptozotocin-induced diabetic rats. J. Basic Clin. Physiol. Pharmacol., 30(4), 2019. DOI: https://www.doi.org/10.1515/ jbcpp-2018-0140

Magariños, A. M. \& McEwen, B. S. Experimental diabetes in rats causes hippocampal dendritic and synaptic reorganization and increased glucocorticoid reactivity to stress. Proc. Natl. Acad. Sci. U. S. A., 97(20):11056-61, 2000.
Malone, J. I.; Hanna, S.; Saporta, S.; Mervis, R. F.; Park, C. R.; Chong, L. \& Diamond, D. M. Hyperglycemia not hypoglycemia alters neuronal dendrites and impairs spatial memory. Pediatr. Diabetes, 9(6):531-9, 2008.

Mao, X. Y.; Cao, D. F.; Li, X.; Yin, J. Y.; Wang, Z. B.; Zhang, Y.; Mao, C. X.; Zhou, H. H. \& Liu, Z. Q. Huperzine A ameliorates cognitive deficits in streptozotocin-induced diabetic rats. Int. J. Mol. Sci., 15(5):7667-83, 2014.

Medagama, A. B. \& Bandara, R. The use of complementary and alternative medicines (CAMs) in the treatment of diabetes mellitus: is continued use safe and effective? Nutr. J., 13:102, 2014.

Nitta, A.; Murai, R.; Suzuki, N.; Ito, H.; Nomoto, H.; Katoh, G.; Furukawa, Y. \& Furukawa, S. Diabetic neuropathies in brain are induced by deficiency of BDNF. Neurotoxicol. Teratol., 24(5):695-701, 2002.

Parihar, M. S.; Chaudhary, M.; Shetty, R. \& Hemnani, T. Susceptibility of hippocampus and cerebral cortex to oxidative damage in streptozotocin treated mice: prevention by extracts of Withania somnifera and Aloe vera. J. Clin. Neurosci., 11(4):397-402, 2004.

Patil, R.; Patil, R.; Ahirwar, B. \& Ahirwar, D. Current status of Indian medicinal plants with antidiabetic potential: a review. Asian Pac. J. Trop. Biomed., 1(2):S291-8, 2011.

Piotrowski, P.; Wierzbicka, K. \& Smiaek, M. Neuronal death in the rat hippocampus in experimental diabetes and cerebral ischaemia treated with antioxidants. Folia Neuropathol., 39(3):147-54, 2001.

Pugazhenthi, S.; Nesterova, A.; Jambal, P.; Audesirk, G.; Kern, M.; Cabell, L.; Eves, E.; Rosner, M. R.; Boxer, L. M. \& Reusch, J. E. B. Oxidative stressmediated down-regulation of bcl-2 promoter in hippocampal neurons. $J$. Neurochem., 84(5):982-96, 2003.

Radenkovic, M.; Stojanovic, M. \& Prostran, M. Experimental diabetes induced by alloxan and streptozotocin: The current state of the art. J. Pharmacol. Toxicol. Methods, 78:13-31, 2016.

Sanchez-Vega, L.; Juárez, I.; Gomez-Villalobos, M. J. \& Flores, G. Cerebrolysin reverses hippocampal neural atrophy in a mice model of diabetes mellitus type 1. Synapse, 69(6):326-35, 2015.

Satheeshkumar, N.; Mukherjee, P. K.; Bhadra, S. \& Saha, B. P. Acetylcholinesterase enzyme inhibitory potential of standardized extract of Trigonella foenum graecum L and its constituents. Phytomedicine, 17(34):292-5, 2010.

Stem, M. S. \& Gardner, T. W. Neurodegeneration in the pathogenesis of diabetic retinopathy: molecular mechanisms and therapeutic implications. Curr. Med. Chem., 20(26):3241-50, 2013.

Vats, V.; Yadav, S. P. \& Grover, J. K. Effect of T. foenum graecum on glycogen content of tissues and the key enzymes of carbohydrate metabolism. $J$. Ethnopharmacol., 85(2-3):237-42, 2003.

Vijayakumar, M. V.; Singh, S.; Chhipa, R. R. \& Bhat, M. K. The hypoglycaemic activity of fenugreek seed extract is mediated through the stimulation of an insulin signalling pathway. Br. J. Pharmacol., 146(1):41-8, 2005.

Yadav, U. C. S.; Moorthy, K. \& Baquer, N. Z. Effects of sodium-orthovanadate and Trigonella foenum-graecum seeds on hepatic and renal lipogenic enzymes and lipid profile during alloxan diabetes. J. Biosci., 29(1):81-91, 2004.

Zhang, W. J.; Tan, Y. F.; Yue, J. T. Y.; Vranic, M. \& Wojtowicz, J. M. Impairment of hippocampal neurogenesis in streptozotocin-treated diabetic rats. Acta Neurol. Scand., 117(3):205-10, 2008.

Zhang, Y. W.; Zhang, J. Q.; Liu, C.; Wei, P.; Zhang, X.; Yuan, Q. Y.; Yin, X. T.; Wei, L. Q.; Cui, J. G. \& Wang, J. Memory dysfunction in type 2 diabetes mellitus correlates with reduced hippocampal CA1 and subiculum volumes. Chin. Med. J., 128(4):465-71, 2015.

\section{Corresponding author:}

Dr. Christofer Thomas

Assistant Professor

Department of Physiology

All India Institute of Medical Sciences

Kalyani

West Bengal

INDIA

Received: 03-05-2020

Accepted: 26-06-2020

Email: christofer109@gmail.com 